\title{
Ergonomics Study Of Public Hospital Signage
}

\author{
Ahmad QadriBasri ${ }^{\mathrm{a}}$,RuhaizinSulaiman ${ }^{\mathrm{b}}$ \\ Department Of Industrial Design, Faculty of Design \& Architecture, \\ Universiti Putra Malaysia, \\ Serdang 43400 Selangor, MALAYSIA. \\ Tel: 03-89464034 Fax: 03-89485242 \\ *E-mail:"adrybasri@yahoo.com, ${ }^{\mathrm{b}}$ ruhaizin@putra.upm.edu.my .
}

\begin{abstract}
Keyword:ergonomics,eye-level height, stature height, user preferences, signage height, public hospital building
\end{abstract}

\begin{abstract}
:
Background: Signage provides information and direction. It is important as a medium to show direction in offices and public buildings. It is more crucial for emergency services, specifically hospitals. Incomplete information and confusion of signage are among common issues being raised by the public to hospital management. Objective:This study is carried out to determine user height preferencesof Hospital Kajang's signage and to proposean appropriate height forits future signage. Approach: Thirty five respondents(20male and 15 female) participated in this study. They are aged between 18 to 60 years old with the mean of age at39years old. Their stature height and eye-level height are measured using SECA Stable Stadiometer.They are asked to give a rating using 1-10 scaleon threequestions to measure their preferences towards the present signage.The studied signage is also measured using standard measuring tape. The data is analyzed using SPSS.Results:It is found that 25 respondents $(71.43 \%$ ) agree to say that the height of signage in Hospital Kajang is too highwhile10 of them (28.57\%)disagree. The signage should be $10.5 \mathrm{~cm}$ lower from present height in order to optimize its function for both groups. The proposed signage height should be $187.5 \mathrm{~cm} f$ rom the floor. Conclusion:The present signage in Hospital Kajang requires necessaryheight readjustment to satisfythe majority of its staffs and visitors. The improvement is vital to ensure the signage meet the directional purpose.
\end{abstract}

\subsection{Introduction}

Signage is an important element in helping and giving directions to users in large public buildings. A large building that has many sections or areas need an effective signage system so that there will be no confusion among users that leads to difficulty and discomfort in finding ways. Furthermore, good signage system helps to save time and makes the activities easily done. Therefore, signage system is very important in public buildings, especially thosewith a large amount of visitors and users, such as hospitals, shopping complex and government buildings.

This paper will focus on the effectiveness of signage systemavailable in government hospitals. Kajang Hospital was chosen in this study since this hospital meets the problem statement mentioned earlier in this study.Based on information presented by the management of Hospital Kajang, users or patients at this hospital in 2011 has reached up to 23,000 people not including visitors and hospital staff itself. With such number of users, a very effective signage system is needed to facilitate the users in this hospital, which has overall 24 sections that covers the management, clinical and sub-clinical.

In order tosolve the problem of ineffectiveness signage system at this hospital, several factors have been identified. One of the factors is the height of the signage in hospital building which isnot compatible with the ergonomic factors of hospital's users. Signage height is closely related to eye level height, which will influence the level of easy-reading height towards the signage provided. This will also affect the effectiveness of the signage system at this hospital and 
causesdifficulties among its users. Thus, the problem need to be solved to ensure the hospital is able to provide an effective signage system in line with its vision to make the hospital an excellent medical center.

Furthermore, signage is important in pointing direction and giving information to the users especially when it comes to health and emergency services. [1] stated that signage consists of eyecatching and can be easily identified that conveniently direct visitors to the destinations. Signage is also often associated with a symbol that indicates the direction or place of destination.[2] said that studies have shown that signage has considerable impact upon way finding behavior that must be included in the overall plan configuration of a building.

A study involving emergency signs with three scenarios have been conducted by [3] to prove that signage does help way finding tasks and the form matters. A year before that, [4] found similar results and concluded that a significant improvement in signage comprehension was discovered when text was added. This case study shows the importance of signage in providing information to users effectively and how to create a systematic physical setting. However, it has been noted by some publics that frustration caused by way finding difficulties not only provoke a negative opinion of the physical setting but that it also affects the perception of the public itself and the services offered in that setting [5].

A hospital should not just simply provides signage since the same problems may still occurs. Research and perfect planning should be conducted to increase way findings. This was supported by [6] that simply implementing signage within facilities, such as hospitals, does not necessarily improve people's way finding experience. For that reasons there are numbers of improvement have been made to solve the signage issues. Increasing the contrast of arrows, enlarging the area of the sign and changing the aspect ratio of the sign may increase the maximum distance at which effective identification can be attained [7].

Meanwhile [8] stated that signage involving human forms has also been found to produce high comprehension results. In addition, [9] found that both signage design and illumination conditions affect the visibility of signage. Besides, the changes in visibility that result from changes in sign, and print size, abstract concept, luminance and the interactional effect of visual angle all need to be considered in signage design.

Similar regulatory information suggested by [10] to achieve effective graphic communication, such as establishing consistency in sign placements and graphic layouts, coding areas by using color and memorable signs, using easily understood "plain" language and using established pictographs with color and words to facilitate comprehension of written messages on the signage.

Healthcare signage is widely used internationally to communicate to people with different languages, disabilities and ages, which typically results in confusion and even anger [11]. They have concluded that the signage confusion among the users will be increase in the future due to constant expansion of hospitals. This expectation has also been agreed by some medical personnel. In the meantime, nurses also felt that there was too much signage within hospitals and that caused the users became immune to the signs and may not have paid attention to all of the meanings [12].

[13] stated that visual signage and digital tools can make aspects of ubiquitous computing technologies be visible and give impact to visual design. His study explore how visual interfaces have been designed and mediated within a design-research project that looked at technologies for mediating between digital media and the physical environment. However, his study needs to connect the modes, media, and materials in exploring multiple, multimodal mediations in which the visualization of ubiquitous technologies need to be made manifest. This study implies that bindings 
and distinctions between design processes, visual mediations, symbols and signs must be emphasized for creative and communicative signage.

In general, this study will identify the right way of installing signage which suits the eyes level height, composition and placement. This study will be focusing only on installation of signage for pedestrian at the public hospital chosen including strategies, framework and methods as mentioned by some scholars above which can contribute for better visual connectivity.

\section{Methods}

There are 35 respondents in this study which consist of 20 males and 15 femaleswith the mean of age at 39 years old. All of the respondents are included in one set of sample group to represent all users in Hospital Kajang. They are patients, visitors and staff at the hospital. All respondents were normal and do not suffer from any disability that may affect their level of eye height. They are aged 18 to 60 years to ensure there is no further growth among the respondents.All respondents involved are Malaysians, since the focus of the study is to investigate the effectiveness of signage height towards Malaysian users in Hospital Kajang. The purpose of the study was later explained to therespondents prior to beginning the study and all respondents gave informed consent.

Closed-end questions were used in this study. The first thing that is obtained from a respondent isthe demographic information such as gender, age, nationality, race, and place of residence. Then, the stature height andeye level height of the respondent are measured (Figure 1 and Figure 2). Theeyes must be 90 degrees to the front. This position is important to ensure standing eyes level height measurement is accurate.Stature height and eye-level height are measured using the SECA217 Stable Stadiometer (Figure 3). This toolwas chosen due to its functions and easy to handle and carry ability.In addition, the adjustable spacer is easy to adjust so that both measurements can be measured along.

In the meantime, the height of signage is also measured. Signage height is measured using Standard 8 Meter Measuring Tape (Figure 4). The measurement of signage height has been recorded to be compared with the height of standing eyes level.

Next, on the questionnaires, the respondents will be asked about their satisfaction towards signage system and they should mark their level of satisfaction according to the scale given, that is from 1 (extremely disagree) to 10 (extremely agree).From the scale provided, satisfaction measurement can be determined. The scale is important to identify the level of their satisfaction level if they were low, medium or high. The differences of scale given by the respondents can also help in showing that the effectiveness of the signage system at the hospital.The same process of collecting data was carried out at another public hospital, Hospital Serdang. This aims to create a comparison of data obtained from both hospital.

From this survey, the level of user satisfaction in this hospital directions will be examined and will further determined whether the hospital need some improvement or modification in terms of signage planning to be more effective.Distributed questionnaires werefocused on the height of the hospital signage. In addition, convenienceof signage height wasalso asked in the questionnaire. Then, the easy reading of signage was also measured in this questionnaire based on the scale provided. 


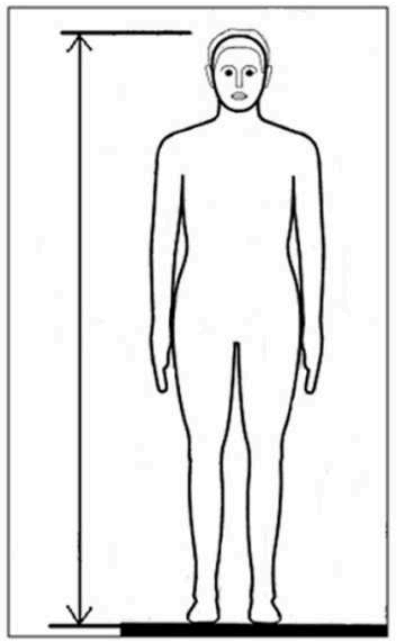

Fig. 1 Stature height

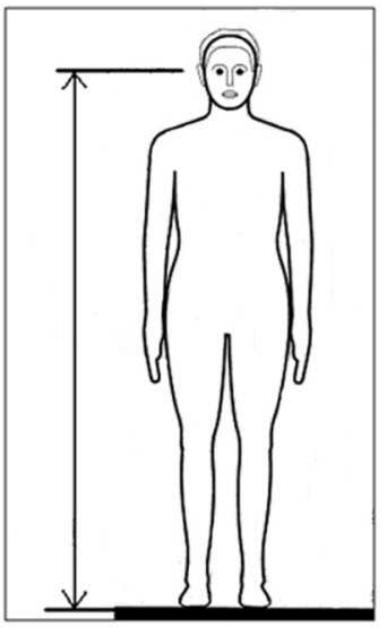

Fig. 2 Eye-level height

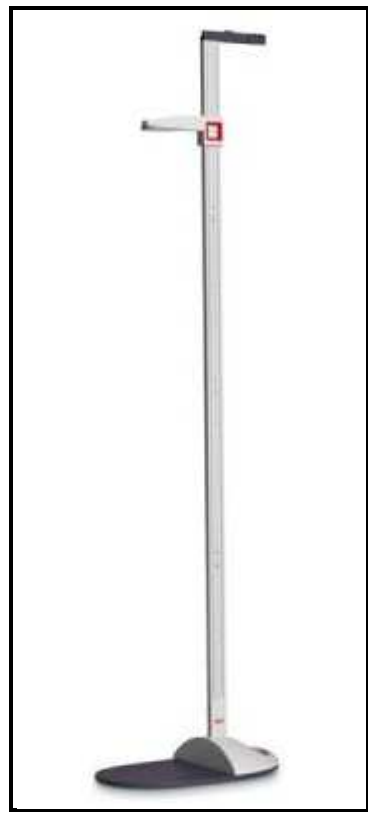

Fig. 3 SECA217 Stable Stadiometer.

Source:http://www.seca.com/english/uk/home/products/details/seca/ 


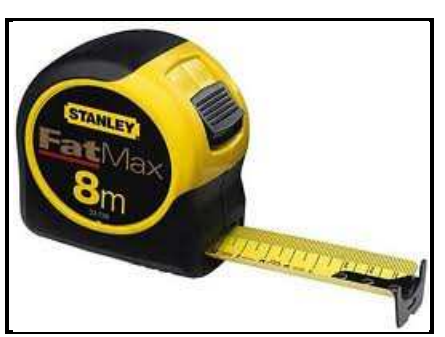

Fig.4 Standard 8Meter Measuring Tape.

Source: www.google.com.my/imgres
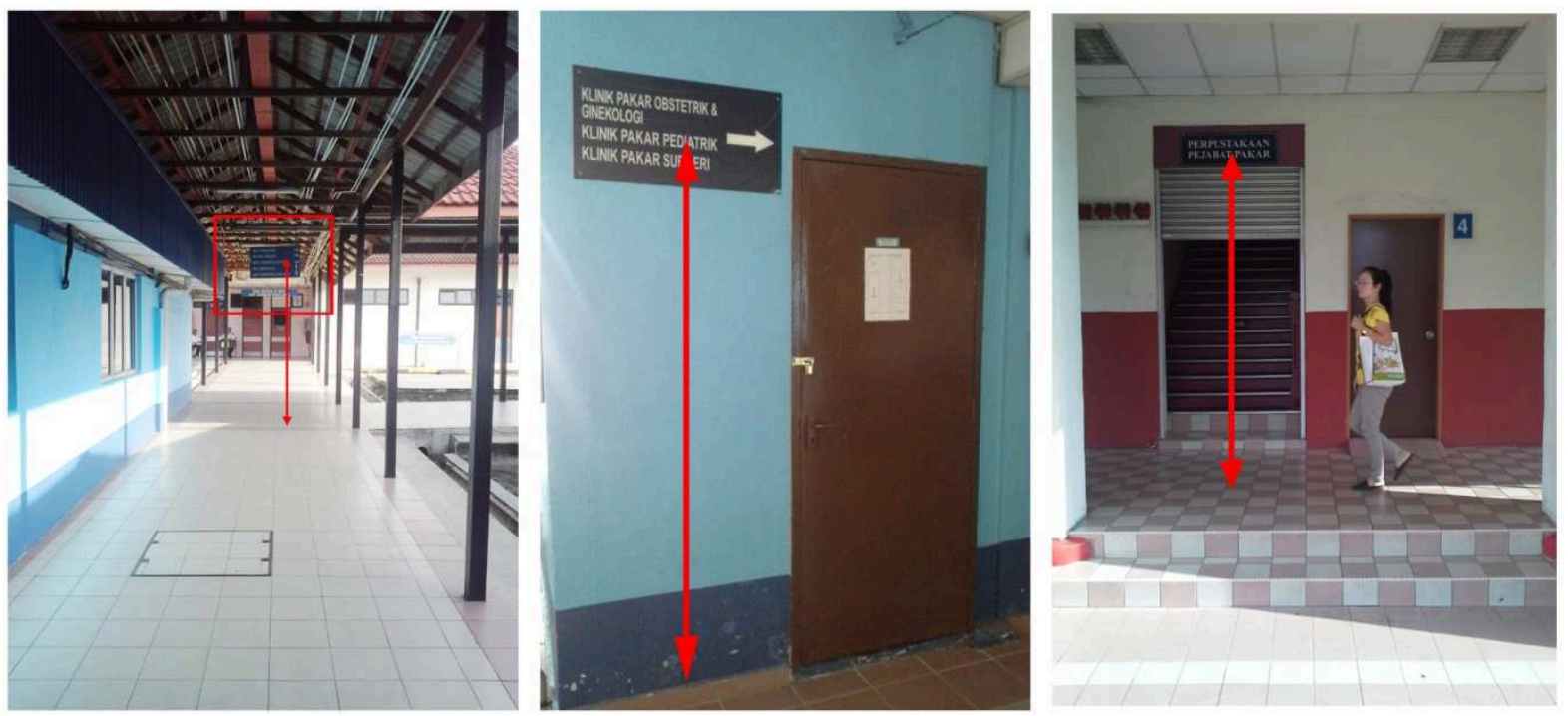

Fig. 5 Signage height in Hospital Kajang

\section{Results}

The survey datawere analyzed using Statistical Product and Service Solutions (SPSS) software. Some important data are recorded to prove the findings.

Table 1Descriptive Statistics

\begin{tabular}{|l|r|r|r|r|r|}
\hline & $\mathrm{N}$ & \multicolumn{1}{|c|}{ Minimum } & Maximum & \multicolumn{1}{c|}{ Mean } & Std. Deviation \\
\hline StandingEyesLevelHeight & 35 & 130.50 & 163.70 & 150.4000 & 8.21100 \\
StatureHeight & 35 & 139.50 & 175.00 & 160.9943 & 8.80531 \\
Valid N (listwise) & 35 & & & & \\
\hline
\end{tabular}

Rating of 8 mean 'high', 9 is 'very high' and rating 10 for 'extremely high'.

The study was conducted on a sample of 35 respondents. From Table 1, the minimumstanding eyes level height of the respondents is $130.50 \mathrm{~cm}$ and the maximum is $163.70 \mathrm{~cm}$. Mean of eye level height is $150.40 \mathrm{~cm}$. Thus, the standard deviation for standing eyes level height is 8.21 .

Based on Table 1 as well, stature height of the lowest among the respondents is $139.50 \mathrm{~cm}$ and the minimum height is $175.00 \mathrm{~cm}$. The mean among the respondents stature height is $160.99 \mathrm{~cm}$. Therefore, the standard deviation is 8.81 . 
Table 2One-Sample Test

\begin{tabular}{|c|c|c|c|c|c|c|}
\hline & \multicolumn{6}{|c|}{ Test Value $=8$} \\
\hline & \multirow[t]{2}{*}{$\mathrm{t}$} & \multirow[t]{2}{*}{$\mathrm{df}$} & \multirow[t]{2}{*}{ Sig. (2-tailed) } & \multirow[t]{2}{*}{ Mean Difference } & \multicolumn{2}{|c|}{$\begin{array}{l}\text { 95\% Confidence Interval of the } \\
\text { Difference }\end{array}$} \\
\hline & & & & & Lower & Upper \\
\hline SF4 & -2.606 & 34 & .013 & -1.34286 & -2.3899 & -.2958 \\
\hline
\end{tabular}

Table 3Statistics

\begin{tabular}{|ll|r|r|}
\hline & $\begin{array}{c}\text { Signage } \\
\text { Factor 4 } \\
\text { (SF4) }\end{array}$ & $\begin{array}{l}\text { StandingEyesLev } \\
\text { elHeight (SELH) }\end{array}$ \\
\hline $\mathrm{N}$ & Valid & 35 & 35 \\
Mean & Missing & 0 & 0 \\
Std. Deviation & & 6.6571 & 150.4000 \\
Minimum & & 3.04807 & 8.21100 \\
Maximum & & 1.00 & 130.50 \\
Percentiles & 95 & 10.0000 & 163.70 \\
\hline
\end{tabular}

Table 3 shows statistical data on Signage Factor 4 (SF4) in Hospital Kajang which refers to the height of the signage. Table also shows the data on Standing Eyes Level Height (SELH) that was taken from the respondents. Based on these data, some points have been identified. Mean for SF4 is 6.6571 , while the mean for SELH is $150.40 \mathrm{~cm}$. Standard deviation for SF4 is 3.04807 , while for SELH is 8.2110. Minimum scale for SF4 is 1 and the maximum is 10 . SELH minimum height is $130.50 \mathrm{~cm}$ and the maximum height is $163.70 \mathrm{~cm}$.

Table 4 Signage Factor 4 (SF4)

Hospital Kajang

\begin{tabular}{|l|r|r|r|r|}
\hline & Frequency & Percent & Valid Percent & \multicolumn{2}{c|}{$\begin{array}{c}\text { Cumulative } \\
\text { Percent }\end{array}$} \\
\hline Extremely Low & 5 & 14.3 & 14.3 & 14.3 \\
Very Low & 1 & 2.9 & 2.9 & 17.1 \\
Slightly Low & 1 & 2.9 & 2.9 & 20.0 \\
Moderate Low & 3 & 8.6 & 8.6 & 28.6 \\
Moderate High & 4 & 11.4 & 11.4 & 40.0 \\
Valid & 4 & 11.4 & 11.4 & 51.4 \\
Slightly High & 6 & 17.1 & 17.1 & 68.6 \\
High & 3 & 8.6 & 8.6 & 77.1 \\
Very High & 8 & 22.9 & 22.9 & 100.0 \\
Extremely High & 35 & 100.0 & 100.0 & \\
Total & & & & \\
\hline
\end{tabular}

Table 4 shows the data obtained from the study of Signage Factor SF4 in Hospital Kajang. The scale of 1-5 means denial of SF4, while 6-10 means agree on SF4. From the survey, 28.6\% denied that signage at Hospital Kajang is high,while $71.4 \%$ agreed to say that the signage at Hospital Kajang is high. 
Table 5 Signage Factor (SF4)

Hospital Serdang

\begin{tabular}{|c|c|c|c|c|c|}
\hline & & Frequency & Percent & Valid Percent & $\begin{array}{c}\text { Cumulative } \\
\text { Percent }\end{array}$ \\
\hline \multirow{9}{*}{ Valid } & Extremely Low & 1 & 2.9 & 2.9 & 2.9 \\
\hline & Slightly Low & 1 & 2.9 & 2.9 & 5.7 \\
\hline & Moderate Low & 4 & 11.4 & 11.4 & 17.1 \\
\hline & Moderate High & 6 & 17.1 & 17.1 & 34.3 \\
\hline & Slightly High & 4 & 11.4 & 11.4 & 45.7 \\
\hline & High & 9 & 25.7 & 25.7 & 71.4 \\
\hline & Very High & 4 & 11.4 & 11.4 & 82.9 \\
\hline & Extremely High & 6 & 17.1 & 17.1 & 100.0 \\
\hline & Total & 35 & 100.0 & 100.0 & \\
\hline
\end{tabular}

Table 5 shows the data obtained from the study of Signage Factor SF4 in Hospital Serdang. The scale of 1-5 means denial of SF4, while 6-10 means agree on SF4. From the survey, 17.1\% denied that signage at Hospital Serdang is high, while $82.9 \%$ agreed to say that the signage at Hospital Serdangishigh.

Table 6Standing Eye LevelHeight (SELH)

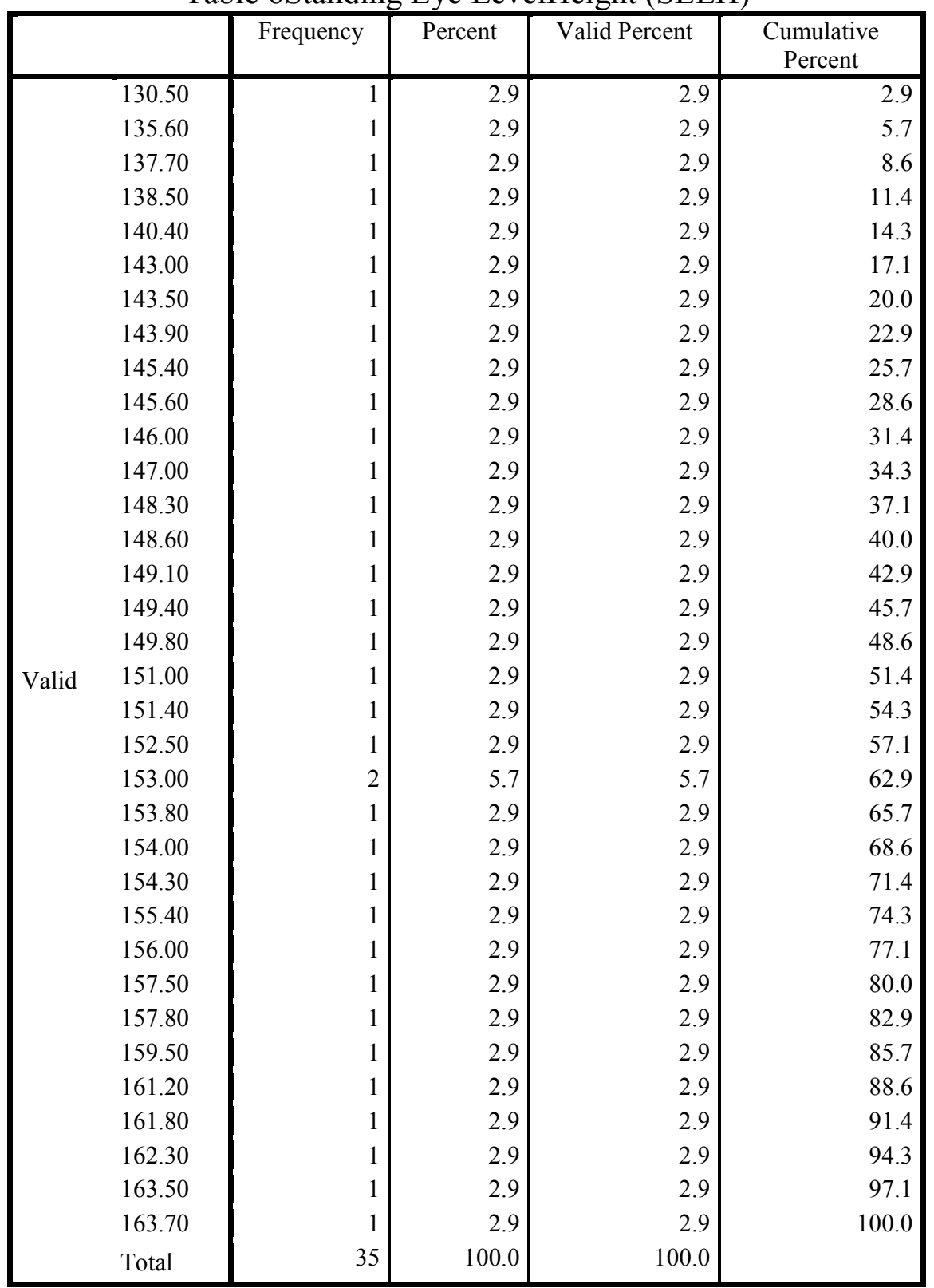


Table 6 shows the data obtained from the study of Standing Eyes Level Height (SELH). The distance elevation points obtained from 35 respondents involved is $130.50 \mathrm{~cm}$ to $163.70 \mathrm{~cm}$.From the data, the range of appropriate signage height could be estimated.

From this study, it is found that 25 respondents( $71.43 \%)$ agree with the present signage height should be lower while 10 of them (28.57\%) disagree. The signage should be $10.5 \mathrm{~cm}$ lower from present height in order to optimize its function for both groups. The proposed signage height should be 187.5 cmfrom the floor.

\section{Discussion}

The study was conducted todetermine user height preferences of Hospital Kajang's signage and to propose an appropriate height for its future signage. Data acquisition involved stature height measurement, standing eyes level height measurement, the frequency of dealing in the hospital, and the height of signage which named as SF4. Based on demographic data, gender factors do not influence the result of the study. It is found that men's height is not necessarily higher than women's. The age does not affect the height of the selected respondent because they do not experienced any further changes in their stature height as mentioned earlier. Respondentsthat live in or nearKajangare morefamiliar withthe direction and orientation of the hospital and this cause them to beless sensitive with the signage issues.

Stature height among respondents is reached $175.00 \mathrm{~cm}$ and the lowest is $139.50 \mathrm{~cm}$. In fact, stature height will affect the standing eyes level height. When the stature height is higher, the standing eyes level height of arespondentwill be higher. The difference between stature height and standing eyes level height is commonly between $9 \mathrm{~cm}$ to $14 \mathrm{~cm}$. These differences occur due to differences size of forehead.

Similar to the case of respondents that staying near to Kajang, some respondents admitted that they were not really sensitive with signage issues as they are working and dealing at the hospital almost every day. They are very familiar with the direction and the route of the hospital without referring to the signage. Thus, they do not face any trouble or problem while dealing or finding ways in the hospital. It can be said that familiarity may influence the effect of signage system. This can be examined in further study. However, during the survey, they agreed that the signage height is very high as compared to their standing eyes level height.

From studies that have been made at HospitalSerdang, the similarresult has been obtained. $82.9 \%$ of the respondents have expressed signage at Hospital Serdangis high. Results obtained from both hospitalsprove that signage in public hospitals need standard setting of height to suit the user.

Numbers of respondentsthat mentioned signage is too high at some areasin the HospitalKajangare 25 out of 35 respondents. They specified the location, which are along the path to the wards and specialist clinics. The small size of the signage requires them to stand near to the signage to read the directions, but when they stand too close to the signage, they need to look up higher from their eyes level height.This proved that the signage at this hospital is not appropriate to the eyes level height among the users.

\section{Conclusion}

This study found that the present signagein Hospital Kajangrequired necessaryheight readjustment to satisfy majority of its staffs and visitors. The improvement is important to ensure the signage meet the purpose of its use. The readjustmentwould enable users to find specific 
directionof the hospital's departments. In addition, good signage could reduce stress and is less time consuming to the users who seek medical treatment or other urgent services.

\section{References}

[1] Harkness, L., 2008. What Exactly Is ‘Wayfinding?’ Main Street News: \#235, Dec. 20.

[2] Garling, T., Book, A., Lindberg, E., 1986. Spatial orientation and way finding in the designed environment: a conceptual analysis and some suggestions for postoccupancy evaluation. Journal of Architecture, Plans and Resources 3, 55-64.

[3] Tang, C.H., Wu, W.T., Lin, C.Y., 2009. Using virtual reality to determine how emergency signs facilitate way finding. Applied Ergonomics 40, 722-730.

[4] Scialfa, C., Spadafora, P., Klein, M., Lesnik, A., Dial, L., Heinrich, A., 2008. Iconic sign comprehension in older adults: the role of cognitive impairment and text enhancement. Canada Journal on Aging 27 (3), 253-265.

[5] Passini R., (1996), Wayfinding design: logic, applicationand some thoughts on universality. Design Studies Vol 17 No 3, 319-331.

[6] Rousek J.B., \& M.S. Hallbeck, (2011), Improving and analyzing signage within a healthcare setting.Applied Ergonomics 42, 771-784.

[7] Collins, B.L., 1991. Visibility of exit directional indicators. Journal of the Illuminating Engineering Society 20 (1), 117-133.

[8] Lesch, M.F., 2008. A comparison of two training methods for improving warning symbol comprehension.Applied Ergonomics 39, 135-143.

[9] Foster, J.J., Afzainia, M.R., 2005. International assessment of judged symbol comprehensibility. International Journal of Psychology 40 (3), 169-175.

[10] Muhlhausen, J., 2006. Signage Plays an Important Part of Wayfinding. ADA Signs Channel.Retrieved from: http://www.signweb.com/index.php/channel/6/id/1433/.

[11] Cowgill, J., Bolek, J., 2003. Symbol Usage in Health Care Settings for People with Limited English Proficiency: Part One, Evaluation of Use of Symbol Graphics in Medical Settings. JRC Design, Scottsdale, AZ.

[12] Dykes, P.C., Carroll, D.L., Hurley, A.C., Benoit, A., Middleton, B., 2009. Why do patients in acute care hospitals fall? Can falls be prevented? The Journal of Nursing Administration 39 (6), 299-304.

[13] Morrison A., \&Arnall T., (2011), Visualizations of Digital Interaction in Daily Life. Computers and Composition $28,224-234$. 